\title{
DIMENSIONES DE GÉNERO DE LOS MERCADOS DE DERECHOS DE AGUA Y TIERRA EN EL DISTRITO DE RIEGO 101 CUXTEPEQUES, CHIAPAS
}

\author{
Laura Elena Ruiz Meza \\ laura.r.meza@gmail.com \\ Universidad de Ciencias y Artes de Chiapas
}

\section{RESUMEN}

Se analizan las dimensiones de género de los procesos de mercantilización de los derechos agrarios y los de agua para regadío en el área de influencia del Distrito de Riego 101 Cuxtepeques, que se localizan en la Región Frailesca de Chiapas. En el contexto de la individualización y privatización de los recursos naturales, se identifican los mecanismos de mercado que vulneran el derecho de las mujeres a la propiedad sobre los recursos naturales. Se sostiene que, en el marco de las relaciones y estructuras de poder existentes, los mercados de derechos de agua y tierra recrean mecanismos de exclusión social e inequidad de género en los procesos de gestión de los recursos naturales a nivel local.

Palabras clave: género, mercados de agua, derechos de agua y tierra, Chiapas.

\begin{abstract}
We analyze the gender dimensions of the commodification of land and water rights for irrigation in the area of 101 Cuxtepeques Irrigation District, in Frailesca region of Chiapas. In the context of individualization and privatization of natural resources, identify market mechanisms that violate the right of women to ownership of natural resources. It is argued that, in the context of relationships and existing power structures, markets for land and water rights recreate mechanisms of social exclusion and gender inequality in the management of natural resources at the local level.
\end{abstract}

Keywords: gender, water markets, water and land rights, Chiapas. 


\section{INTRODUCCIÓN}

Durante las últimas décadas, las políticas hídricas orientadas a reducir la inversión y la participación pública en la gestión del agua han impulsado estrategias que combinan la descentralización por la vía de la transferencia de infraestructura hidroagrícola con la privatización a través de mecanismos de mercado para asignar concesiones y derechos de agua. Por su parte, las reformas al sector agrario han estado dirigidas a estimular la mercantilización y privatización de la tierra. Ambos procesos se han inscrito en un contexto de profundas transformaciones en el sector rural caracterizado por la desregulación económica y la liberalización de los recursos naturales.

Las políticas de ajuste estructural, y lo que estas significan en términos del retiro del Estado de sus funciones relacionadas con la provisión de servicios básicos y de regulación de la intervención privada en el manejo de los recursos colectivos, como el agua y la tierra, han sido objeto de severos señalamientos debido a que la apropiación de los recursos está determinada por los intereses de los sectores con mayor poder y ya no son regulados ni por el Estado (Rico, 2006) ni por la sociedad civil ni las instituciones comunitarias.

Particularmente, las asambleas ejidales y comunitarias habían sido instancias que regulaban el uso y distribución de los recursos naturales. Sin embargo, en los últimos años -sobre todo a partir de la titulación agraria realizada por el Programa de Certificación de Derechos Ejidales y Titulación de Solares (Procede)- las asambleas locales, como instancias normativas, han estado perdiendo su capacidad para hacer cumplir los acuerdos locales en torno al manejo y asignación de los recursos de interés colectivo y, más aún, se ha erosionado su poder para regular la renta y venta de derechos agrarios y de derechos de agua, proceso en el que han intervenido intereses individuales y empresariales ajenos a las comunidades rurales. 
En algunos ejidos y comunidades se ha estipulado que las ventas de derechos de tierra y agua sean notificadas a la asamblea, sobre todo si se enajena toda la superficie que ampara el título de propiedad. Sin embargo, la renta de parcelas no está sujeta a ningún tipo de regulación. En cualquier caso, ni la renta ni la venta suelen informarse a la asamblea, y más bien imperan mecanismos no formales en los tratos agrarios.

Los postulados neoliberales acerca de los beneficios esperados de la individualización, la privatización y la certificación de los derechos agrarios y de derechos de agua, en cuanto a mayores oportunidades de acceso a los recursos naturales y al incremento de la eficiencia en su uso, no se han cumplido, para los sectores empobrecidos de la población rural y mucho menos para las mujeres. Las campesinas no están accediendo a la tierra y al agua de manera significativa y autónoma, sino que, en todo caso, la obtienen mediante prácticas de herencia a través de los varones, sus padres o esposos, en quienes continúa recayendo la toma de decisiones sobre el uso y control de los recursos y los bienes patrimoniales del hogar.

En un contexto en el que la privatización de los recursos naturales se incrementa y va despojando de su base de subsistencia a amplios grupos de la población, se presenta como un imperativo conocer los impactos sociales y ambientales de los mecanismos de mercado en aquellos sectores expuestos a condiciones de vulnerabilidad, de manera particular sobre las mujeres campesinas y jefas de hogar; más aún al considerar que los mercados presentan sesgos sociales y de género, como se demostrará en los siguientes apartados.

El presente artículo aborda las dimensiones de género de los mercados de derechos de agua y tierra en el Distrito de Riego 101 Cuxtepeques, localizado en el municipio La Concordia, Chiapas. Se identifican y analizan los mecanismos de mercado que vulneran el derecho de las mujeres a la propiedad sobre los recursos naturales y algunos de sus impactos sociales y ambientales. 
Los resultados que aparecen en este trabajo forman parte de una investigación de mayores dimensiones (Ruiz, 2009). Los ejes de análisis son el grupo doméstico, las relaciones de género y la tenencia de recursos naturales. El estudio se realizó en cuatro ejidos del distrito de riego, seleccionados por sus dimensiones y por tener mayor presencia de población femenina poseedora de tierra y adscrita al padrón de usuarios del agua de riego, y por ser ejidos en los que se ha llevado a cabo el proceso de certificación agraria. Los datos que se presentan fueron obtenidos mediante diversos instrumentos de tipo cuantitativo y cualitativo. Se aplicó una encuesta sociodemográfica para conocer el tamaño, composición y jefatura de los grupos domésticos, los recursos que poseen, las actividades productivas y reproductivas que realizan sus integrantes, las prácticas de herencia de la tierra y los mecanismos de movilidad de la tierra, entre otros aspectos. Mediante entrevistas a autoridades ejidales y sujetos clave, se recabó información sobre las instituciones locales de gestión de los recursos naturales, se identificaron las transformaciones agrarias y aspectos relativos a los procesos locales de adopción de decisiones. Las entrevistas a profundidad con mujeres campesinas permitieron conocer sus experiencias de participación en los mercados de derechos de agua y tierra que vulneran su acceso y control a los recursos naturales.

\section{¿QUÉ SON LOS MERCADOS DE DERECHOS DE AGUA Y TIERRA?}

Desde la Conferencia Internacional sobre Agua y Ambiente realizada en 1992 se han establecido nuevas bases para el diseño y modificación de las políticas de gestión de los recursos hídricos, a partir de lo que se conoce como los Principios de Dublín, los cuales han considerado al agua un recurso vulnerable, finito, y un bien con un valor económico en todos sus usos (WWC, 2000).

El mercado de aguas, en términos del mercado de derechos de propiedad privada, se inscribe en la asignación del recurso a los distintos usos que esta tiene: urbano, agrícola, industrial, pesca, minería, generación de energía, recreación, y se define como instrumento 
de mercado en la medida en que un uso tiene cierta predominancia y excluye a otros. Cuando el agua es vista como un bien económico escaso, que además de tener un valor de uso tiene un valor de cambio y genera acumulación de capital, adquiere la característica de ser apropiable por el mayor postor.

Así, los mercados de agua tienen lugar cuando a este recurso se le asigna un precio determinado mediante el libre intercambio de algún título de propiedad para usarla, ya se trate de un derecho, un permiso o una concesión. Son las interacciones entre compradores y vendedores de estos títulos las que constituyen los mercados de agua (Donoso et al., 2004:19). Como todo bien, el valor económico del agua suele estar asociado a su disponibilidad y a su costo de oportunidad en función de los valores que se den a los distintos usos y a su calidad y cantidad.

Desde la perspectiva gubernamental, los mercados de agua pretenden ser mecanismos para reasignar los derechos de agua entre sectores que compiten por el recurso hacia usos alternativos de mayor valor; de tal forma que los usuarios con concesión valoren los costos de oportunidad de utilizar el agua o venderla a otros que no tienen concesión. Asimismo, buscan incrementar su uso eficiente mediante la reducción de la demanda, propiciar la reactivación de la agricultura de riego a través de la tecnificación y modernización de los sistemas de irrigación, y aumentar la motivación de los agricultores para facilitar la reconversión productiva a través del cambio a cultivos más rentables. Los mercados de agua se basan en una noción de propiedad privada y su precio se define en términos monetarios en una negociación (Ramos, 2004: 10-11).

Sin embargo, el argumento de introducir las fuerzas del mercado para armonizar los intereses económicos con el uso eficiente del agua no se sostiene en la práctica, pues los mercados de agua no solo no han garantizado el manejo adecuado de este recurso, sino que han desplazado la producción de cultivos básicos y despojado de sus tierras a los campesinos y campesinas mediante el acaparamiento de las mejores áreas de cultivo, como 
se revisará en este artículo. De acuerdo con Ahlers (2005:56), el paradigma neoliberal de la competencia y la eficiencia, al intervenir en la reasignación de los derechos de propiedad a los recursos naturales, tiene diferentes implicaciones en sectores sociales marcados por el género, la clase y etnicidad.

Alhers (2003: 380) también sostiene que el agua es un bien con características particulares que da lugar a que las transacciones comerciales sean particularmente conflictivas en comparación con otros recursos. La fluidez del agua, el ser un bien público, el que demande un manejo colectivo y, sobre todo, el estar vinculado estrechamente a la supervivencia, da lugar a que el establecimiento de derechos formales de propiedad sobre este líquido pueda resultar un tanto ambicioso y poco eficaz. El agua posee múltiples usos y usuarios que le imprimen diferentes valores, de ahí que sea un bien poco conmensurable, es decir, "medible" como una mercancía con valor de cambio. Al tomar decisiones sobre el uso y destino del agua, los usuarios no solo se basan en un análisis de costo-beneficio, sino que entran en juego una serie de valores históricos, culturales, sociales y ambientales asociados a este bien colectivo. De esta manera, señala Alhers (2005:58) que la comercialización del agua es una abstracción removida de su contexto social, pues ignora que los recursos naturales están interrelacionados y poseen múltiples significados sociales.

Además de ello, los derechos al agua están frecuentemente relacionados con otros, como los derechos a la tierra, los sociales, culturales y ambientales, y son afectados por una diversidad de normativas jurídicas y consuetudinarias que legitiman las exigencias sociales al agua mediante una amplia heterogeneidad de referentes. La diversidad de factores que intervienen en las formas en que las poblaciones se relacionan con los recursos hídricos muestra una complejidad tal que no puede soslayarse por parte de los marcos jurídicos formales establecidos. ${ }^{1}$

Autoras como Meinzen-Dick y Pradhan (2002:7) señalan que las concepciones rígidas de los derechos de propiedad concebidas solo como un título emitido por el gobierno no 
prevén la complejidad y dinamismo de los derechos de propiedad, los cuales están sujetos a cambios constantes debido a la pluralidad de normativas, a las incertidumbres sociales y políticas y a los cambios en las estrategias de reproducción de los grupos sociales. Los derechos son producto de negociaciones y disputas, y se ven influenciados por las relaciones de poder político y económico. De manera particular, los derechos al agua son, además, dinámicos y flexibles, y están sujetos a negociaciones frecuentes debido a las fluctuaciones en la disponibilidad de tal recurso.

Pese a esta complejidad, el establecimiento de los títulos de concesión sobre el agua bajo un esquema de propiedad privada se erige como el mecanismo privilegiado para regular los derechos de propiedad y facilitar las transacciones entre agricultores eficientes y no eficientes. Así, los mercados de agua dan como resultado una distribución inequitativa de los derechos al generar una aguda concentración de los mismos en un estrato de agricultores con mayor poder y capacidad financiera para comprarlos a los productores de menores recursos, con frecuencia a precios ínfimos. Esto significa que los mercados de agua distan de ser eficientes al no existir una libre competencia y por presentar elementos monopolistas cuando un puñado de compradores son quienes imponen los precios, como lo identificaron Fortis y Alhers (1999) para el caso del Distrito 016 en La Comarca Lagunera, y como se analizará en este artículo para el caso del Distrito de Riego 101 Cuxtepeques, en Chiapas.

La reforma del sector hídrico en nuestro país se impulsó de manera paralela con cambios en las políticas agrícolas y agrarias. Una de las iniciativas más significativas en materia de política agraria fue la modificación del Artículo 27 constitucional en 1992 y la reformulación de la Ley Agraria, que facilitaron la liberalización de los mercados de tierras. Tales reformas jurídicas trastocan de manera fundamental la estructura de los derechos de propiedad sobre la tierra y con ello las relaciones sociales agrarias. El eje central del cambio legislativo es el cuestionamiento al régimen de propiedad social y la promoción de una reforma agraria de mercado (De Ita, 2006). Hoy en día, al ser el mercado el principal 
mecanismo para la disposición de los financiamientos al campo y para acceder a la tierra, se crean esquemas que permiten la titulación de las propiedades individuales y su eventual privatización, como el Programa de Certificación de Derechos Ejidales y Titulación de Solares Urbanos (Procede). Se introduce también la posibilidad de convertir la propiedad social de la tierra en propiedad privada a través de la adopción del dominio pleno, lo que implicaría la desaparición del ejido (León, et al., 2005:22).

Desde la perspectiva de los organismos financieros internacionales y los gobiernos neoliberales, la reasignación de derechos de propiedad por medio del desarrollo de los mercados de tierra tiene su fundamento en varios supuestos que se basan en la teoría evolutiva de los derechos de propiedad. Según varios autores (Scott, 1996; Bouquet, 1999), estos supuestos son:

- Al aumentar la escasez de los recursos se genera un sistema de incentivos que tiende a establecer derechos de propiedad, individuales, exclusivos y libremente transferibles.

- La regularización del título de propiedad otorga certeza a los agricultores y permite estimular la inversión, y con ello el desarrollo tecnológico, la eficiencia y la productividad en el sector agropecuario.

- $\quad$ El título de propiedad facilita la venta del predio, lo que permite una mejor asignación y uso de los recursos.

- Un mayor acceso al mercado de crédito puede garantizarse mediante la obtención del título de propiedad.

- $\quad$ La certificación de tierras aumenta la capacidad de los gobiernos para recabar impuestos.

Diversos estudios realizados en la región latinoamericana han mostrado que tales supuestos no se cumplen con la liberalización de los mercados de tierras. Para Scott (1996), la validez de esos argumentos es cuestionable y no tienen la intención de disminuir la pobreza rural. Los efectos de la titulación están muy condicionados por los factores locales, donde acuerdos informales entre parientes o vecinos evitan problemas asociados con la ausencia de títulos. En regiones de minifundio y donde la tierra es de mala calidad, los costos sociales de titulación pueden ser mayores que sus beneficios y esta no garantiza un mayor acceso a los financiamientos. Asimismo, en muchas comunidades empobrecidas, el 
mercado de tierras no podrá ser dinámico y en todo caso el grueso de las transacciones se efectuará entre parientes y vecinos.

El mercado de tierras como instrumento principal de la política de tierras no solo no ha permitido que los campesinos accedan a ella, sino que ha profundizado la desigualdad existente. En su estudio sobre el mercado de tierras ejidales, Concheiro y Diego (2003) han señalado que los cambios en el marco legal agrario y la ejecución de la política de titulación de la tierra han dinamizado e incrementado su movilidad mediante mecanismos de compraventa y arrendamiento, tanto al interior de las comunidades como por agentes externos a ellas. Los autores señalan que se aprecia una tendencia de concentración selectiva de la tierra, que adquiere la forma de un neolatifundismo construido en torno a los grupos de poder local y regional, capitalistas agrarios, agroindustrias transnacionales y grandes ganaderos. Tal tendencia parece apreciarse también en el Distrito de Riego 101 Cuxtepeques.

\section{CONTEXTO LOCAL}

En la llamada Depresión Central de Chiapas, por la que corren el río Grijalva y sus afluentes, se localiza el Distrito de Riego 101 Cuxtepeques. La región también es conocida con el nombre de Valles Centrales, constituida por amplias llanuras y numerosos valles, uno de ellos es el Valle de los Cuxtepeques. El sistema de riego inicia su operación en 1980 y cuenta con un solo aprovechamiento, el río Cuxtepec, y una obra de cabeza, la Presa Juan Sabines. La capacidad útil de almacenamiento de la presa es de 73 millones de $\mathrm{m}^{3}$. En el ciclo agrícola 2008-2009 se destinó el 95\% del agua a las actividades agropecuarias y el 4.1\% a usos domésticos, pues la de la presa se distribuye entre diversos poblados del municipio La Concordia, entre ellos la cabecera municipal. El distrito de riego abarca una superficie irrigable de 8,278 hectáreas, de las cuales el 94.8\% corresponde al sector social (ejido) y el 5.4\% a la propiedad privada, integrada por medianos productores y ganaderos locales. En el área de influencia del distrito se encuentra gran parte del territorio de ocho ejidos: La Tigrilla, Benito Juárez, Ámbar de Echeverría, Diamante de Echeverría, 
Guadalupe Victoria, Nueva Libertad, Independencia y Juan Sabines. Los usuarios del agua de riego del sector ejidal son 1,664, de los cuales 1,430 son hombres (86\%) y 234 mujeres (14\%). ${ }^{2}$ En 1995, la Comisión Nacional del Agua (CONAGUA) transfirió la administración de la infraestructura y la operación del riego a los agricultores usuarios, para lo cual se constituyó la Asociación de Usuarios Productores del Distrito de Riego Cuxtepeques, A. C., organización a quien se le otorgó el título de concesión para el aprovechamiento del agua (CONAGUA, 2009).

Si bien el cultivo de pasto para ganadería y el de maíz continúan siendo los más importantes en términos de la superficie sembrada e irrigada, las estadísticas revelan que en particular la superficie de maíz ha sufrido una drástica caída de casi el 50\% en los últimos ciclos agrícolas, reducción que indica la crisis por la que atraviesa una de las actividades productivas que en otros tiempos fue la base de la riqueza regional. Los sistemas de cultivo de maíz de riego son intensivos en el uso de agroquímicos y semillas híbridas. La producción de maíz para semilla está adquiriendo importancia, actividad que se realiza mediante la renta y compra de tierras de riego. Por su parte, el establecimiento de plantaciones de sandía y de papaya experimenta un crecimiento significativo a partir del 2000 y se van estableciendo como los cultivos con mayor valor e importancia comercial mediante el arriendo de derechos de tierra y agua.

Entre las principales causas que originan el mercado de derechos de agua y tierra en la región se encuentra el paulatino abandono de las actividades agropecuarias. La ausencia de políticas públicas de fomento, crédito e inversión productiva en el sector y los efectos nocivos de la apertura comercial derivada del Tratado de Libre Comercio con América del Norte (TLCAN) han dado lugar a que la rentabilidad de las actividades agropecuarias se haya desplomado, agudizada por el desequilibrio generado por el alto costo de los insumos agrícolas y la caída de los precios de los productos. La ausencia de precios de garantía y de disponibilidad de capital para invertir en la parcela ha generado una mayor incertidumbre entre los campesinos. 
Así, las motivaciones para rentar o vender derechos están relacionadas con los pocos incentivos económicos para continuar cultivando las tierras, aunque sigue vigente el arraigo cultural a la tierra y la necesidad de cultivarla para la subsistencia. Los campesinos optan más por los ingresos obtenidos vía la transferencia de derechos -aunque estos sean reducidos - que invertir dinero y trabajo en cultivar más allá de lo necesario para obtener el sustento. ${ }^{3}$ A ello se suma el poco interés de los jóvenes en las actividades agrícolas, quienes se muestran más dispuestos a emigrar. El estancamiento de la producción agropecuaria ha incrementado la migración a las ciudades del norte del país y a los Estados Unidos de Norteamérica, como expresión de la diversificación de las estrategias de subsistencia de las familias campesinas y de la pobreza rural.

En la zona de estudio la renta y venta de derechos de agua está estrechamente ligada a la de la tierra. Las diferentes modalidades de renta, la vigencia del contrato y el precio dependerán del tipo de tierra, del cultivo a producir y del poder de negociación de quien arriende y venda, no de la disponibilidad del agua. El precio de renta era, en abril de 2007, de mil pesos por hectárea para el cultivo de maíz en tierras de riego y de 500 pesos en temporal. Los precios de venta de las tierras de riego han experimentado un crecimiento sostenido derivado de la demanda, pero también del proceso de certificación agraria (acontecido durante la segunda mitad de la década de los noventa) que ha incrementado el valor nominal de la tierra en la región. En el 2006, una hectárea de riego se vendía en 50 mil pesos; para el 2008 se cotizaba hasta en 80 mil pesos.

La compra y renta de tierras y agua con fines comerciales se efectúa para la producción de pastos para la ganadería, de sandía, papaya, arroz y de semilla de maíz y de frijol, cultivos de alta rentabilidad para los cuales se destinan las tierras de riego. Para las empresas que se han establecido en la región, la renta suele ser más ventajosa que la compra, porque implica menores inversiones y la posibilidad de concluir con el contrato de arriendo al disminuir la productividad de la tierra luego de varios años de cultivo intensivo. 
El mercado de agua en el distrito está siendo dominado por la presencia de monopolios por rama de producción. Los principales arrendatarios en la región están representados por empresas que establecen esquemas de agricultura por contrato y tienen suma influencia en la demanda y fijación de precios de estos derechos.

\section{MAÍZ Y FRIJOL PARA SEMILLA}

Una de la empresas que se ha destacado por la renta de derechos de agua y tierra en varias regiones de agricultura irrigada del país es la Cooperativa Productores Asociados de Semillas (PROASE), que nace en el año 2001 a iniciativa de ex-trabajadores de la Productora Nacional de Semillas, la entonces empresa paraestatal que vendió a la cooperativa las instalaciones y maquinaria de procesamiento de la semilla. Esta asociación se ha dedicado a la producción de semillas híbridas y mejoradas de maíz, de sorgo y de frijol generadas por el Instituto Nacional de Investigaciones Forestales, Agrícolas y Pecuarias (INIFAP). El mecanismo de renta del agua y de la tierra adopta las características de una agricultura de contrato. La empresa aporta la semilla, los insumos, la asistencia técnica y el transporte, igualmente establecen el precio de compra. Por su parte, el arrendador campesino aporta su tierra y trabajo. En caso de siniestros, la empresa solo condona el costo de la semilla, pero todos los insumos deben ser pagados. Con este trato, los riesgos son asumidos casi por entero por el agricultor, no por la empresa.

Las semillas producidas por (PROASE) son comercializadas a través del gobierno del estado, quien las distribuye por medio de los programas de subsidio al campo, que en Chiapas adopta el nombre de «Maíz Solidario». Este programa ha sido sumamente cuestionado por las organizaciones de productores orgánicos porque las semillas mejoradas requieren de altas dosis de fertilizantes químicos para garantizar su rendimiento, insumo agrícola que sabotea los intentos de las organizaciones campesinas por producir alimentos libres de agroquímicos y por reducir los costos de producción. En opinión de los campesinos, la semilla que proporciona el gobierno a través de ese programa es poco productiva en comparación con las de las transnacionales y no suele ser usada. 


\section{AGRICULTURA DE CONTRATO PARA LA PRODUCCIÓN DE PAPAYA}

En el distrito de riego el cultivo de papaya ha experimentado un acelerado crecimiento en los últimos años. En la producción están involucradas varias empresas privadas de capital nacional. Para el establecimiento de la plantación, las empresas compactan extensiones de hasta 70 hectáreas mediante la renta de tierra y derechos de agua en aquellos ejidos donde las dotaciones agrarias son mayores, como Benito Juárez y La Tigrilla. Este estudio permitió identificar a varias mujeres ejidatarias de estas localidades que rentan toda su propiedad para el cultivo de ese producto.

En un esquema de agricultura de contrato, las empresas rentan tierra por un periodo de tres a cinco años; los precios de renta, para el año 2007, oscilaban entre seis y siete mil pesos por hectárea al año. Los productores de la fruta no se interesan por la compra de tierras, ya que la plantación deja de tener productividad y rentabilidad a los cinco años de haberse establecido, debido al alto consumo de agroquímicos que provoca resistencia de los insectos plaga y degrada y contamina las tierras. Durante el periodo de cosecha, las empresas incrementan su demanda de jornaleros y para el proceso de empacado ocupan predominantemente mano de obra femenina.

\section{IMPULSO A LA PRODUCCIÓN DE ARROZ}

En un intento por aprovechar la escasa rentabilidad de los cultivos tradicionales, en el año 2006 otro proyecto sin precedentes en el distrito de riego pretendió ser impulsado mediante la renta de derechos de tierra y agua, encabezado por la empresa Compañía Arrocera Covadonga, S.A. de C.V., líder en producción nacional de arroz y propietaria de numerosos centros de acopio en el sur y occidente del país. Los planes de la empresa preveían el cultivo del cereal en 1,500 hectáreas en toda la entidad. Sus metas en el distrito de riego Cuxtepeques incluían establecer un nuevo centro de acopio y abarcar una extensión de más de 500 hectáreas. En su esquema contractual, la arrocera pagaría la renta de la tierra y aportaría el paquete tecnológico requerido, incluida la maquinaria y el mercado. Para el 
ciclo productivo 2008-2009 ya había alcanzado la cifra de 325 hectáreas de riego. Aunque esta iniciativa no ha tenido hasta ahora el éxito esperado, se puede afirmar que representa una amenaza a la preservación de los derechos a la tierra y el agua en manos del campesinado.

Nuevos proyectos de este tipo ven en esta zona irrigada una oportunidad para prosperar. Tal es el caso de la producción de oleaginosas que pretende ser destinada a la generación de biocombustibles, y que se empieza a establecer en la zona con el impulso de las instituciones públicas del sector agropecuario.

\section{EL MERCADO DE DERECHOS DE AGUA EN EL DISTRITO DE RIEGO}

En México, la Ley Federal de Derechos en Materia de Agua (2002), a través del Registro Público de Derechos de Agua (REPDA), tiene la función de asegurar la legalidad de los derechos, resolver eventuales problemas y ser fuente de información para el funcionamiento de los mercados de agua. Desde las reformas a la Ley de Aguas Nacionales en 1992 se permite la transmisión de derechos derivados de las concesiones de agua legalmente vigentes e inscritos en el (REPDA). La Ley de Aguas Nacionales reformada en el año 2004 establece que los títulos de concesión podrán ser transmitidos a terceras personas en forma definitiva o temporal, y se indica explícitamente en el Artículo 35 que la transmisión de los derechos de aprovechamientos de aguas deberá convenirse conjuntamente con la transmisión de la propiedad de la tierra (CONAGUA, 2002).

En el caso de un distrito de riego, la transmisión de derechos entre los miembros de una misma Asociación de Usuarios, o a terceras personas que los sustituyan como usuarios en los mismos terrenos, se efectuará sin mayor trámite, según el Artículo 104 del Reglamento de la Ley de Aguas Nacionales. Solo están reguladas las transmisiones de derechos de uso del agua cuando estos se otorguen a personas físicas o morales de fuera del distrito de riego, para lo cual se requerirá de la aprobación de la asamblea general de la Asociación de Usuarios. Sin embargo, esta normativa no siempre se aplica, pues generalmente se hace el 
trato entre el vendedor y el comprador de los derechos, y una vez consumado el arreglo en ocasiones se notifica a la asociación, como ha sucedido en el Distrito de Riego 101 Cuxtepeques.

Desde que se creó el Procede en los ejidos del distrito, a mediados de la década de los noventalos agricultores y ejidatarios de mayor poder económico y político han estado presionando a las asambleas ejidales y a la Asociación de Usuarios para que se adopte el dominio pleno. ${ }^{4}$ Ello implicaría un uso del agua sin la intermediación o aprobación de ninguna organización o instancia de autoridad comunitaria ya que, según el artículo 56 de la Ley de Aguas Nacionales, al adoptarse el dominio pleno se tendrán por transmitidos los derechos de aprovechamiento del agua para el riego, e implica que el propietario podrá usar las aguas como concesionario individual, a quien se le otorgará un título de concesión particular. En estos casos, los agricultores que transmitan la titularidad de la tierra cederán también sus derechos de agua.

Los diversos actores sociales entrevistados —autoridades ejidales, técnicos del distrito de riego e incluso arrendatarios - coinciden en afirmar que tanto la renta como la venta de tierras han estado creciendo en los ejidos, sobre todo después de que se ha creado el Procede. El incremento en la movilidad de la tierra por medio de la compra-venta y el arrendamiento parece establecer una tendencia hacia la reducción de la superficie sembrada en manos de los pequeños campesinos. Uno de los técnicos del distrito señalaba que tienden a desaparecer los pequeños campesinos que poseen entre tres y cinco hectáreas, y crecen los agricultores propietarios de 30 a 50 hectáreas, lo que da cuenta de un proceso de transferencia de derechos del sector social al privado.

A partir del 2004, cuando la Ley de Aguas Nacionales establece que el padrón de usuarios debe estar permanentemente actualizado y la jefatura del distrito acepta que existe un significativo incremento de la venta y de los traspasos de derechos en los ejidos que impide conocer el número real de usuarios del agua, la Asociación de Usuarios instituye como 
obligatoria la notificación por escrito de los cambios en la asignación de derechos de propiedad de la tierra y el agua. A pesar de que ahora se considera legal, la renta y venta no suele reportarse ni a las autoridades ejidales, ni a la Asociación de Usuarios, ni a la oficina del Registro Agrario Nacional. Con frecuencia las transacciones de tierra y agua no son anunciadas a las autoridades agrarias por diversas razones, entre ellas porque el traspaso o cesión de derechos entre familiares suele no incluir la firma de documentos y en algunos tratos agrarios no se establecen contratos escritos si son arreglos temporales entre vecinos y familiares. En los ejidos, por acuerdo de asamblea, la venta, pero no la renta, es la única que debe notificarse cuando se transmita toda la superficie que ampara un título de propiedad. Sin embargo, tal aviso no siempre se efectúa debido a que, como parte del acuerdo que se celebra, el vendedor prefiere no dar aviso del cambio de propietario para continuar recibiendo el subsidio del Programa de Apoyos Directos al Campo (Procampo), pues es quien está inscrito en el padrón de dicho programa.

Si bien no refleja una visión completa de las transferencias de derechos por las razones ya mencionadas, el registro de actualización de usuarios que posee la jefatura del distrito permite obtener cierta información acerca de las dimensiones y tipo de transferencias que se han realizado en los ejidos y que han sido notificadas.

Según ese registro, de 2003 a mayo de 2007 se habían reportado 124 cambios en la titularidad de los derechos agrarios y de aguas, de los cuales 65 (52.4\%) son enajenaciones o ventas de derechos y 59 (47.6\%) son cesiones de derechos, efectuadas generalmente por el titular para anticipar la herencia de la tierra entre los hijos varones ya casados, entre otros casos que no implican transacción comercial. Las transferencias totales (toda la superficie que ampara el certificado parcelario) fueron levemente menores que las parciales (se vendió o cedió solo una parte del derecho parcelario), 59 frente a 65, lo que indica que la división del derecho parcelario se efectúa aunque esté prohibida por la Ley Agraria cuando el titular tiene que vender parte de la parcela para enfrentar una emergencia o empezar a heredar el derecho agrario entre sus descendientes, entre otros motivos (Cuadro 1). 
Cuadro 1. Transferencia de derechos de agua y tierra en el Distrito de Riego 101 Cuxtepeques.

\begin{tabular}{|c|c|c|c|c|c|c|c|}
\hline Año & Total & Venta & $\%$ & Cesión & $\%$ & $\mathbf{T T}$ & $\mathbf{T P}$ \\
\hline 2003 & 18 & 12 & 66.7 & 6 & 33.3 & 10 & 8 \\
\hline 2004 & 19 & 12 & 63.2 & 7 & 36.8 & 9 & 10 \\
\hline 2005 & 56 & 25 & 44.7 & 31 & 55.3 & 26 & 30 \\
\hline 2006 & 23 & 13 & 56.5 & 10 & 43.5 & 10 & 13 \\
\hline A mayo de 2007 & 8 & 3 & 37.5 & 5 & 62.5 & 4 & 4 \\
\hline Totales & 124 & 65 & - & 59 & - & 59 & 65 \\
\hline
\end{tabular}

Fuente: Elaboración propia sobre la base de los datos obtenidos del archivo del Distrito de Riego 101 Cuxtepeques, 2007.

Un aspecto de suma relevancia es que de los 124 traspasos de derechos registrados en el periodo de 2003 a 2007, el 80\% se dio entre hombres y solo el 3.2\% se estableció entre mujeres, probablemente de madres a hijas. Mientras que las transferencias de un hombre a una mujer fueron del orden del 7.2\%, de una mujer a un hombre el porcentaje sube a 9.6\%. Estas cifras indican que las transmisiones de derechos han beneficiado mayoritariamente a los varones (89.6\%), y no solo no han facilitado el acceso de las mujeres a la propiedad de la tierra, sino que incluso han contribuido a que las mujeres pierdan sus parcelas. Cabe señalar que en el caso de los contratos de compra-venta aparece la firma de la esposa del vendedor en muestra de acuerdo con la venta.

Con las transmisiones de derechos de tierra parciales, el número de usuarios del agua de riego crece, pero no así el número de derechos de agua. Estos se otorgan por derecho parcelario; si este se divide entre propietarios parciales, los derechos no se incrementan, de acuerdo con lo establecido por el reglamento de la Asociación de Usuarios y la Ley de Aguas. 


\section{PERFIL SOCIODEMOGRÁFICO DE LAS MUJERES PROPIETARIAS}

Dado que interesa analizar cómo han sido vulnerados por el mercado los derechos de acceso y propiedad de los recursos de las mujeres campesinas, se eligió realizar el estudio con mujeres que poseen recursos en la zona de influencia del Distrito de Riego 101 Cuxtepeques. Para tener un acercamiento a este tipo de población femenina se tomó como primera referencia el padrón de usuarios del agua de riego de la Asociación de Usuarios Productores del Distrito de Riego 101 Cuxtepeques, A.C. A la fecha del estudio, los usuarios del sector ejidal sumaban 1,664, de los cuales 1,430 eran hombres (86\%) y 234 mujeres $(14 \%)^{5}$

La investigación se realizó en cuatro de los ocho ejidos: La Tigrilla, Benito Juárez, El Ámbar de Echeverría y El Diamante de Echeverría, por ser los de mayores dimensiones, por tener mayor presencia de población femenina poseedora de tierra y adscrita en el padrón de usuarios, y por ser ejidos en los que se ha llevado a cabo el proceso de certificación agraria. En los cuatro ejidos considerados en el estudio se encuentra el 73.85\% del total de la membresía de la Asociación de Usuarios; asimismo, tiene presencia el 78.16\% de la membresía masculina y el $77.45 \%$ de la femenina.

Las mujeres registradas en la mencionada asociación incluyen usuarias que son productoras por poseer tierras y derechos al agua, pero también se encuentran registradas las que no son productoras. En este último caso se trata de mujeres que han rentado o vendido sus derechos a la tierra y al agua, prestanombres de familiares varones e incluso que han cambiado de residencia. Asimismo, en las comunidades se encuentran algunas que no aparecen registradas como usuarias en el padrón, pero que en los hechos son usuarias, agricultoras y/o administran la producción en las parcelas de labor. En este grupo se ubican quienes tienen un acceso no formal a la tierra y al agua; es decir, que pueden no ser propietarias de los recursos en un sentido legal. Por estas razones, los datos acerca del número de mujeres vinculadas con la producción agrícola y con la posesión y propiedad de la tierra se complementaron con los registros sobre los sujetos agrarios existentes en cada ejido y mediante entrevistas con los 
técnicos que distribuyen el agua de los canales de riego a las parcelas, llamados «canaleros». Así, de las 182 mujeres inscritas en el padrón de usuarios, 121 eran usuarias del agua de riego y agricultoras (Cuadro 2).

Cuadro 2. Mujeres con derechos al agua y a la tierra en los ejidos de estudio.

\begin{tabular}{|l|c|c|}
\hline \multicolumn{1}{|c|}{ Ejido } & $\begin{array}{c}\text { Mujeres inscritas en el } \\
\text { padrón (1) }\end{array}$ & $\begin{array}{c}\text { Mujeres en el padrón usuarias } \\
\text { del riego (2) }\end{array}$ \\
\hline El Diamante & 19 & 11 \\
\hline El Ámbar & 19 & 23 \\
\hline La Tigrilla & 67 & 42 \\
\hline Benito Juárez & 77 & $\mathbf{1 2 1}$ \\
\hline Total & $\mathbf{1 8 2}$ & 45 \\
\hline
\end{tabular}

Fuentes: (1) Padrón de la Asociación de Usuarios (abril de 2006), (2) Canalero (mayo 2006)

A partir del dato de las 121 usuarias del riego, se definió una muestra estadísticamente representativa de 50 mujeres en los cuatro ejidos de estudio para aplicar un cuestionario que permitió recabar información sobre las características sociodemográficas de los grupos domésticos y datos socioeconómicos, como las prácticas de herencia, renta y venta de derechos agrarios y derechos de agua, entre otros.

En los siguientes renglones se presenta la condición de las mujeres respecto a su acceso a los recursos naturales, con el propósito de ofrecer un contexto sobre su participación en los mercados de tierra y agua.

A través de las costumbres y prácticas de herencia que favorecen a los varones se ha generado una distribución desigual de los recursos entre los géneros, prácticas basadas en las relaciones de parentesco, conyugales y de residencia patrilineales y patrivirilocales (Deere y León, 2002). En los cuatro ejidos, en promedio, solo el 12\% de los ejidatarios son mujeres y no todas tienen el título a su nombre. Las posesionarias apenas superan el $20 \%{ }^{6}$ El control sociolegal de los derechos a la tierra y al agua recae en los hombres, y ello 
muestra a quiénes detentan el poder y qué representan esos derechos dentro de los grupos domésticos (Cuadro 3).

Cuadro 3. Sujetos agrarios por ejido.

\begin{tabular}{|l|c|c|c|c|c|c|}
\hline \multicolumn{1}{|c|}{ Ejido } & Ejidatarios & $\begin{array}{c}\text { \% } \\
\text { Hombres }\end{array}$ & $\begin{array}{c}\text { \% } \\
\text { Mujeres }\end{array}$ & Posesionarios & $\begin{array}{c}\text { \% } \\
\text { Hombres }\end{array}$ & $\begin{array}{c}\text { \% } \\
\text { Mujeres }\end{array}$ \\
\hline $\begin{array}{l}\text { Benito } \\
\text { Juárez }\end{array}$ & 221 & 88.7 & 11.3 & 205 & 77.6 & 22.4 \\
\hline La Tigrilla & 145 & 89.6 & 10.4 & 437 & 80.5 & 19.5 \\
\hline El Ámbar & 182 & 86.3 & 13.7 & n.d. & - & - \\
\hline El Diamante & 203 & 87.2 & 12.8 & n.d. & - & - \\
\hline
\end{tabular}

Fuente: Presidente del Comisariado Ejidal, 2006

En contraste con el reducido acceso que tienen las mujeres a los derechos formales a la tierra y el agua, su participación en los procesos productivos y en tareas de regadío es destacada. Entre un 40 y un 60\% de las mujeres están a cargo del proceso productivo y con frecuencia realizan actividades y tareas agropecuarias diversas; en este grupo destacan las ejidatarias y posesionarias jefas de hogar, pues las mujeres que tienen pareja intervienen de manera parcial y no tienen control sobre el proceso de producción, que recae en sus parejas. Una importante proporción de mujeres declaró asumir labores de riego de manera permanente y eventual, entre el $18 \%$ y el $40 \%$, lo que revela que esta labor no es exclusiva de los hombres y que ellas han participado en el riego y continúan haciéndolo en función de su edad, estado civil y de la disponibilidad de mano de obra masculina familiar y contratada. Las mujeres suelen tener a su cargo la administración y supervisión del predio, toman las decisiones sobre el proceso productivo y contribuyen a los ingresos familiares de diversas maneras. Al ser viudas, pero también a causa de la migración masculina, las campesinas han visto multiplicadas sus responsabilidades $\mathrm{y}$ han asumido tareas consideradas culturalmente como propias de los varones. 
Entre las mujeres con tierra y usuarias del riego se presenta un alto porcentaje de viudas, sobre todo en las ejidatarias (50\%), y una importante proporción de hogares encabezados por mujeres, entre el $60 \mathrm{y}$ el $84 \%$. El 70\% de las mujeres ejidatarias son mayores de 50 años. Entre las posesionarias, en cambio, predominan las mujeres menores de 50 años (el $75 \%$ ) y casadas (56\%), aunque el $60 \%$ encabezan su hogar debido a la migración de sus esposos (Ruiz, 2009).

En las comunidades de estudio, en promedio, el 63\% de las ejidatarias han accedido a la tierra por la vía de la herencia al enviudar y en la edad adulta; en cambio, el $42.9 \%$ de las posesionarias la obtuvieron por ese medio. Las ejidatarias suelen tener propiedades mayores de cinco hectáreas (71\%), tanto de riego como de temporal; mientras que las posesionarias en su mayoría (56.3\%) tienen parcelas menores de cinco hectáreas.

Las normas y prácticas de género constituyen una importante restricción para que las mujeres ejerzan su derecho a poseer recursos. Tanto las leyes agrarias como las costumbres de herencia de la tierra han considerado al hogar encabezado por un varón como la unidad social beneficiaria de la tierra, y aunque las mujeres tienen derecho legal a la dotación agraria, esta normativa poco se aplica (Ruiz, 2005). En los ejidos de estudio, solo el 16.3\% de las mujeres propietarias recibieron la tierra por dotación o por asignación de tierra vacante debido a que tenían familia a su cargo.

Las relaciones de poder implícitas en los patrones de división sexual del trabajo permiten entender por qué los hombres y las mujeres tienen espacios de vida, responsabilidades y derechos distintos y jerarquizados. La reclusión de las mujeres al ámbito doméstico invisibiliza su involucramiento en actividades comunitarias y productivas fuera del hogar. Además de las tareas domésticas y de las labores agropecuarias, el 60\% de las campesinas realizan actividades comerciales por cuenta propia y desde su hogar, con el fin de incrementar los ingresos familiares (Ruiz, 2009). De esta forma, las mujeres, en especial quienes asumen la jefatura de su hogar, están a cargo de múltiples actividades que forman 
parte de las estrategias de reproducción social de sus hogares, en un contexto regional en el que la producción agropecuaria no es ya la única fuente de ingresos familiares.

Las cargas de trabajo de las mujeres también impiden su movilidad y participación en los espacios públicos de toma de decisiones sobre la gestión del agua. Ninguna mujer usuaria del riego mencionó participar en las reuniones de la Asociación de Usuarios y del Comité Hidráulico, ni ocupa cargos en estos espacios. El costo de oportunidad del tiempo invertido para asistir es diferente para hombres y mujeres, ya que sus prioridades no son las mismas y generalmente ellas no pueden transferir algunas de sus responsabilidades a sus esposos, a diferencia de ellos, que sí suelen delegar tareas en ellas.

La adscripción de las mujeres al ámbito privado presupone que los lugares de reunión masculina no son apropiados para ellas y el riesgo de no respetar esta normativa tiene costos en su integridad moral, así que los roles y espacios de acción delimitados social y culturalmente para hombres y mujeres son asumidos como legítimos por ambos. La ideología de la feminidad y masculinidad se impone para mantener a las mujeres al margen de los procesos de toma de decisiones, en un distrito donde la gestión del agua es centralizada por las instituciones gubernamentales (Ruiz, 2011).

La ideología androcéntrica que prevalece en las normativas de acceso a la propiedad de la tierra y de división del trabajo por género da lugar a que las mujeres accedan a la tierra en su condición de viudas, jefas de hogar y a edad avanzada, además de generar un pobre reconocimiento social a su labor como agricultoras y de impedir su participación política. El conjunto de estas circunstancias adversas las coloca en una situación de aguda vulnerabilidad para conservar sus derechos a la tierra y al agua, sobre todo en un contexto de crisis de las actividades agropecuarias y de liberalización de los recursos naturales. Su vulnerabilidad se agrava cuando gran parte de los ingresos de los hogares encabezados por mujeres se obtienen de la renta de derechos. Destaca el caso del ejido Benito Juárez, donde el 100\% de las ejidatarias declaró recibir gran parte de sus ingresos por la renta de su tierra. 
En el ejido La Tigrilla, el 54.5\% de las ejidatarias indicó recibir ingresos por la renta de sus tierras, y en el ejido El Diamante la cifra se eleva al 60\% de las ejidatarias (Ruiz, 2009). Esta dependencia económica contribuye a reducir su poder de negociación en las transacciones de sus derechos de tierra y agua, y revela los motivos por los que ellas aceptan tratos no formales y desventajosos, y rentan sus derechos con mayor frecuencia que los hombres. Se aprecian diferencias entre ejidatarias y posesionarias, pues estas últimas reportaron mayores ingresos derivados del comercio y las remesas, y en menor proporción de las actividades agrícolas y de la renta de la tierra. Esto se debe a que ellas se dedican directamente a las actividades de pequeño comercio, pero sobre todo a las pequeñas dimensiones y pobre calidad de sus parcelas, y porque estas son administradas por sus parientes masculinos.

Las mujeres campesinas, ejidatarias y posesionarias no solo obtienen de la tierra su sustento, sino que también les permite mantener su arraigo a la comunidad. Pese a las circunstancias adversas en las que viven, la propiedad de la tierra les otorga cierto control sobre sus medios de vida. Muchas mujeres manifestaron su deseo de no emigrar a la ciudad a vivir con sus hijos porque se vería comprometida su autonomía.

La evidencia revisada destaca elementos clave acerca de las relaciones de género en la agricultura irrigada. Uno de ellos es que los derechos formales al agua y a la tierra predominan en manos de los hombres, pero otro aspecto importante es que las mujeres que han accedido a recursos productivos desempeñan múltiples tareas, las cuales, además de incrementar sus cargas de trabajo, se realizan en condiciones marginales y adversas que reproducen su posición subordinada por no ser reconocidas como productoras, como mujeres que tienen un papel destacado en las actividades agropecuarias y en la reproducción, tanto de sus hogares como de sus unidades productivas. 


\section{DIMENSIONES DE GÉNERO DE LOS MERCADOS DE AGUA Y TIERRA}

La encuesta aplicada a las mujeres ejidatarias y posesionarias de tierra mostró que ellas han participado en los mercados más como oferentes mediante la renta y la venta de sus parcelas, que como compradoras. Para el caso de los ejidos El Diamante y El Ámbar solo se incluyeron ejidatarias, por ser mayoría entre las mujeres propietarias y usuarias del agua para riego.

En el ejido El Diamante, el 80\% de las ejidatarias ha dado en renta su tierra y en el ejido El Ámbar el 40\%. En el ejido La Tigrilla, el 45.5\% de las ejidatarias ha rentado, así como el 28.6\% de las posesionarias. En el caso de Benito Juárez, el 100\% de las ejidatarias declaró haber rentado toda o parte de su tierra, pero ninguna posesionaria señaló haberlo hecho.

La proporción de mujeres que se ha visto en la necesidad de vender parte de sus parcelas es del 20\% en el ejido El Diamante; en El Ámbar no vendió ninguna ejidataria. En La Tigrilla, el 27.3\% de las ejidatarias y el 14.3\% de las posesionarias lo han hecho, y en Benito Juárez, el $25 \%$ de las ejidatarias y del $100 \%$ de las posesionarias. En los cuatro ejidos, los compradores han sido en su mayoría (75\%) agricultores varones del propio ejido, y en el 25\% de los casos se trató de agricultores externos a la comunidad.

Con respecto a la compra, mientras que en El Diamante ninguna mujer declaró haber comprado tierras, en El Ámbar el 40\% de las ejidatarias lo hizo. En La Tigrilla señalaron haber comprado el $45.5 \%$ de las ejidatarias y el 71.4\% de las posesionarias. En Benito Juárez, el 11\% de las ejidatarias y el 28.6\% de las posesionarias señalaron haber adquirido alguna. Se reportó que las dimensiones de las parcelas obtenidas mediante la compra oscilan entre media hectárea y tres hectáreas, y solo en un 35\% de los casos son tierras de riego (Cuadro 4). 
Cuadro 4. Participación de las mujeres en los mercados de derechos agrarios y de derechos de agua. (Porcentajes)

\begin{tabular}{|l|c|c|c|}
\hline \multicolumn{1}{|c|}{ Ejido } & $\begin{array}{c}\text { Mujeres que } \\
\text { han rentado }\end{array}$ & $\begin{array}{c}\text { Mujeres que } \\
\text { han vendido }\end{array}$ & $\begin{array}{c}\text { Mujeres que } \\
\text { han comprado }\end{array}$ \\
\hline El Diamante N =5 & 80 & 20 & 0 \\
\hline El Ámbar N =5 & 40 & 0 & 40 \\
\hline $\begin{array}{c}\text { La Tigrilla N = 18 } \\
\text { ejidatarias = 11 } \\
\text { posesionarias = }\end{array}$ & 45.5 & 27.3 & 45.5 \\
\hline $\begin{array}{c}\text { Benito Juárez N = } \\
\text { ejidatarias = 13 } \\
\text { posesionarias =9 }\end{array}$ & 100 & 14.3 & 71.4 \\
\cline { 2 - 4 } & 0 & 25 & 11.1 \\
\hline
\end{tabular}

Fuente: Elaboración propia sobre la base de la encuesta sociodemográfica y económica a grupos domésticos, 2007.

Nota: varias mujeres han estado en más de una circunstancia.

En estas comunidades una alta proporción de mujeres ha rentado sus tierras. Destacan las ejidatarias de El Diamante (80\%) y Benito Juárez (100\%). La venta de parcelas también ha sido significativa, en especial para las posesionarias de Benito Juárez, pues el 100\% señaló haber vendido, así como el 27.3\% de las ejidatarias en La Tigrilla. ${ }^{7}$ Estos datos contrastan con la compra de alguna parcela. A simple vista, la relativamente alta proporción de mujeres posesionarias que señaló haber adquirido tierra, 28.6\% en Benito Juárez y el 71.4\% en La Tigrilla, podría sugerir que se han beneficiado con los mercados de tierras; sin embargo, conviene señalar que en su mayoría se trata de pequeñas superficies de temporal y no de riego. A diferencia de las ejidatarias, la mayoría de las posesionarias no están viudas y no tienen en la herencia la principal vía de acceso a la tierra. Además de ello, entre las posesionarias casadas (56.4\%) es frecuente que sea el marido o los hijos mayores quienes trabajen la tierra y tomen decisiones sobre el proceso productivo y los ingresos obtenidos, de tal manera que los eventuales beneficios de ser propietaria para este grupo de agricultoras se ven sensiblemente disminuidos al no participar activamente en la toma de decisiones sobre el uso de los recursos. Así, las posesionarias casadas ejercen menor control sobre la tierra a diferencia de las propietarias de tierra (ejidatarias y posesionarias) que encabezan su hogar por viudez o separación, quienes participan de manera destacada en 
los procesos productivos agropecuarios y tienen mayor influencia en la toma de decisiones en su grupo familiar en torno a los beneficios obtenidos, debido a la ausencia de un varón jefe de hogar.

Las condiciones contractuales en los procesos de renta de derechos difieren entre hombres y mujeres. Mientras que los tratos entre varones suelen involucrar un contrato por escrito, las mujeres establecen acuerdos verbales cuando rentan sus tierras a los agricultores. Las campesinas que rentan su tierra para el cultivo de maíz suelen aceptar el pago en producto, que no va más allá de tres bultos de maíz en mazorca o desgranado para destinarlo al autoconsumo familiar y para alimentar a los animales de traspatio. En estos casos, la negociación del precio incluye un porcentaje de la cosecha.

Las campesinas que poseen algunas cabezas de ganado bovino, con frecuencia, rentan sus pastizales a campesinos de la localidad que tienen un mayor hato ganadero y requieren forrajes, sobre todo en épocas de estiaje. La necesidad de obtener un ingreso por los pastizales que no utilizan, junto a su reducido poder de negociación, da lugar a que las mujeres se vean forzadas a rentar en condiciones y a precios sumamente desventajosos para ellas. No existe un esquema único de contrato para estos casos, el trabajo de campo permitió identificar amplia diversidad de condiciones. Algunas mujeres declararon recibir 40 pesos al mes por cabeza de ganado que se alimenta de sus pastizales durante la temporada de estiaje, es decir, alrededor de seis meses. Algunas otras mujeres señalaron recibir mil pesos por hectárea durante todo el periodo de arriendo (seis meses), cuando se trata de parcela de riego. Si se pretende utilizar como forraje el rastrojo de maíz, el precio se reduce a 500 pesos por hectárea de riego. En otro caso, una ejidataria indicó haber recibido solo dos mil pesos por 13 hectáreas de pasto que rentaba a su primo durante seis meses, precio que aceptó porque incluiría la reparación del cercado del pastizal, labor que la campesina consideraba no poder realizar. 
Entre las razones que las mujeres mencionaron para rentar sus tierras se encuentra su edad avanzada y menor fuerza física para cultivar las parcelas, la falta de mano de obra familiar disponible, además de trabajadores confiables. El alto costo de los insumos agrícolas es otro aspecto que les impide continuar trabajando la tierra. Las mujeres que han vendido parte de sus terrenos argumentan que se han visto en la necesidad de hacerlo por circunstancias de extrema necesidad, con frecuencia para afrontar enfermedades de familiares, eventos que contribuyen a que los precios de venta sean sumamente bajos con respecto a los que se podrían obtener sin el apremio que implica la emergencia. En entrevista, afirmaron que lamentan haberse visto obligadas a vender, pues prefieren conservar sus parcelas debido a que el valor de la tierra se incrementa año con año, por lo que cada vez es más difícil adquirirla. La primera opción que tienen es la venta de algunas cabezas de ganado y por último la de sus parcelas. ${ }^{8}$

Las pocas mujeres que han tenido la oportunidad de adquirir pequeñas superficies declaran haberlo hecho para cultivar granos básicos, tener una fuente de ingresos que les permita enfrentar su vejez y heredar a sus hijos y nietos, en el marco de una cultura campesina de subsistencia que concibe los bienes y el patrimonio familiar como fuente de ahorro y sustento.

En el distrito de riego de la Comarca Lagunera, en el norte del país y en un contexto agrícola diferente al chiapaneco, Alhers (2003: 388) identificó situaciones semejantes al concluir que el acceso al mercado de derechos de agua es distinto para hombres y mujeres, pues el precio pagado a las mujeres es menor al que perciben los hombres; además, ellas tienen que negociar un porcentaje de la cosecha. Al igual que en el distrito de riego Cuxtepeques, con frecuencia las mujeres prefieren recibir el pago en especie para satisfacer necesidades del hogar o comercializar localmente. Asimismo, identificó que las mujeres que rentan y venden el agua y la tierra superan en casi el doble a los hombres, aunque fueron menos propensas que ellos a vender sus derechos de agua por varios ciclos agrícolas: el 57\% de las mujeres frente al 73\% de los hombres; ambos confesaron pesadas y 
difíciles negociaciones con sus compradores y situaciones de venta obligada por el apremio económico que influyeron para disminuir su poder de negociación (Alhers, 2003:388).

A diferencia de lo que sucede en Cuxtepeques, en la Comarca Lagunera las mujeres involucraron a los comisariados ejidales para organizar la venta y no hicieron la negociación directamente con el comprador, razón por la cual ellas recibieron 19\% menos por sus derechos de agua en comparación con los hombres. En su estudio, la autora no identificó a ninguna mujer que haya comprado derechos de agua y tierra, pero los hombres habían comprado ambos (Alhers, 2005:64).

De esta forma, se puede afirmar que los incentivos de las mujeres para participar en los mercados de derechos agrarios y de agua se encuentran inmersos en circunstancias derivadas de sus identidades de género, de edad y de clase, que contribuyen a incrementar su vulnerabilidad al priorizar arreglos no formales en los tratos agrarios y un bajo precio de venta y renta con el fin de obtener algunos ingresos y construir relaciones de apoyo mutuo con sus parientes y con arrendatarios masculinos; relaciones que no dejan de situarlas en situación de suma desventaja.

\section{CONCLUSIONES}

La creciente individualización de los derechos agrarios y de agua presente en el Distrito de Riego 101 Cuxtepeques ha generado que los recursos naturales básicos para la subsistencia se estén trasladando del sector social al sector privado. Con el crecimiento de los mercados de derechos de tierra y agua, la estructura agraria en el distrito se va transformando hacia la coexistencia, dentro de cada ejido, de unidades de producción orientadas a los mercados nacionales e internacionales y de pequeños predios familiares cuya producción se destina al mercado local y al autoconsumo; en este segundo grupo se encuentran las mujeres propietarias de tierra que encabezan su hogar. 
En los ejidos del distrito no existe un marco institucional que reglamente la renta y venta de derechos de tierra y agua. Muchos de los contratos, al ser verbales y no tener reglamentación y supervisión, dan lugar a situaciones de incumplimiento que operan en contra de los intereses de las campesinas que carecen del poder de negociación y de instancias de procuración de justicia para hacer llegar sus quejas. Los mercados se caracterizan por elementos monopolistas que generan relaciones desiguales y desleales en contra de las campesinas que se ven en la necesidad de obtener ingresos complementarios por la renta y venta de sus recursos.

La reasignación de los recursos naturales a través de su mercantilización ha afectado también la cohesión comunitaria, y con ello ha dado lugar a una pérdida de control local sobre la gestión de los recursos, ante la ausencia de soportes que garanticen la conservación y uso adecuado de las tierras y la asignación segura y equitativa del agua.

Los mecanismos de mercado de derechos de agua y tierra reproducen el tipo de relaciones sociales y de poder que caracterizan a la sociedad en la que ellos se inscriben. No solo ahondan las desigualdades sociales, sino que profundizan las inequidades de género. Contribuyen a despojar a las mujeres de un recurso clave para su sustento, al que ha accedido de manera tardía y bajo mecanismos tradicionales marcados por las normativas de género que les impiden gozar de la propiedad de los recursos por derecho propio. Constituyen un elemento más que somete a las mujeres a condiciones de negociación desventajosas, incrementando su dependencia y vulnerabilidad hacia los arrendatarios y compradores.

En el actual contexto neoliberal que considera alienables los derechos de propiedad individuales, Alhers y Zwarteveen (2009) sugieren reflexionar acerca de las ventajas que les proporciona a las campesinas contar con títulos de propiedad formales por presentar el riesgo de despojo. En el artículo se ha argumentado que, en las condiciones sumamente injustas en las que participan las mujeres en los mercados de agua y tierra, es preciso 
cuestionar, no la pertinencia de los derechos individuales para las mujeres, sino los mecanismos legales y culturales prevalecientes en torno a los cuales ellas acceden a los recursos e intentan asegurar sus derechos de propiedad. El derecho individual y formal a los recursos contribuye a garantizar su sustento, las hace menos dependientes de sus parientes masculinos al tener acceso autónomo a recursos económicos y les permite tomar parte en los procesos productivos y de gestión del agua. Sin embargo, la situación de pobreza y escaso poder de negociación de las mujeres inscritas en un sistema cultural de género discriminatorio, junto a la ausencia de procesos democráticos de gestión de los recursos naturales, debilitan su derecho a los recursos naturales.

Reducir las desigualdades de género en el control de derechos a la tierra y el agua, en efecto, no puede reducirse a la sola asignación de derechos formales e individuales para las mujeres, sino que requiere de profundos cambios culturales de todos los actores sociales involucrados en la gestión del agua, además de transformaciones estructurales. Un factor clave en el control de las mujeres sobre los recursos naturales es el reconocimiento y legitimidad social de sus necesidades y prioridades como campesinas, usuarias del riego y productoras, como interlocutoras válidas dentro de los sistemas del riego. El reto reside en desafiar la fuerte asociación cultural e ideológica entre agricultura irrigada y masculinidad (Zwarteveen, 2008). Para vislumbrar cambios se debe ir más allá de los ámbitos formales y trastocar toda una cultura androcéntrica construida en torno a la irrigación y al uso del agua con fines productivos, deconstruir los símbolos culturales que organizan y estructuran las prácticas y representaciones respecto a la artificial división entre esferas masculinas y femeninas con relación a los usos y manejo de los recursos. 


\section{BIBLIOGRAFÍA}

Ahlers, Rodante, 2003, «¿Determinarán las relaciones de género el futuro de la Agricultura de Riego? Relaciones de género y mercados de agua», en Agua, Medio Ambiente y Desarrollo en el Siglo XXI, editado por Ávila, Patricia, El Colegio de Michoacán, Instituto Mexicano de Tecnología del Agua, México, pp. 379-394.

Ahlers, Rhodante, 2005, «Gender Dimensions of Neoliberal Water Policy in México and Bolivia: Empowering or Disempowering?», en Opposing Currents. The Politics of Water and Gender in Latin America, editado por Bennett, Vivienne, Sonia Dávila-Poblete y Nieves Rico, University of Pittsburgh Press, pp. 53-71.

Ahlers, Rhodante y Margreet Zwarteveen, 2009, «The water question in feminism: water control and gender inequities in a neo-liberal era», en Gender, Place \& Culture, vol. 16, núm. 4, pp. 409-426.

Boelens, Rutger, 2008, The Rules of the Game and the Game of the Rules. Normalization and resistance in Andean water control, Wageningen University, Países Bajos.

Bouquet, Emmanuelle, 1999, «Mercado de tierras ejidales en Tlaxcala. Formalidad e informalidad del cambio institucional», en Estudios Agrarios 11, México, pp. 67-106.

Concheiro, Luciano y Roberto Diego, 2003, «Estructura y dinámica del mercado de tierras ejidales en diez ejidos de la República Mexicana», en Políticas y regulaciones agrarias. Dinámicas de poder y juegos de actores en torno a la tenencia de la tierra, coordinado por Léonard, Eric, André Quesnel y Emilia Velázquez, CIESAS, IRD, Porrúa, México, pp. 157-188.

Comisión Nacional del Agua, 2009, Informe de distribución de aguas, Jefatura de Operación del Distrito de Riego 101 Cuxtepeques, Chiapas. 
Comisión Nacional del Agua, 2002, Ley Federal de Derechos en Materia de Agua, México.

De Ita, Ana, 2006, «Land Concentration in Mexico after Procede», en Promised Land. Competing Visions of Agrarian Reform, editado por Rosset, Peter, Raj Patel \& Michael Courville, Food First Books, California, pp. 148-164.

Donoso, Guillermo, A. Jouraviev, H. Peña y E. Zegarra, 2004, Mercados de derechos de agua: experiencias y propuestas en América del Sur, Serie Recursos Naturales e Infraestructura No. 80, CEPAL, Santiago de Chile.

Fortis, Manuel y Rhodante Alhers, 1999, Naturaleza y extensión del mercado del agua en el D. R. 017 de la Comarca Lagunera, México, Serie Latinoamericana No. 10, International Water Management Institute, México.

León, Arturo, Elsa Guzmán, Friné López, Julio Romaní y Laura Ruiz, 2005, Relaciones de Género y Acceso a la Tierra, Espacio Autónomo, A. C. y UAM-Xochimilco, México.

Meinzen-Dick, Ruth y Rajendra Pradhan, 2002, Legal Pluralism and Dynamic Property Rights, Systemwide Program on Collective Action and Property Rights, Working Paper 22, International Food Policy Research Institute, Washington.

Ramos, Sergio, 2004, Mercados de agua, Instituto Mexicano de Tecnología del Agua, México.

Rico, Nieves, 2006, «Género y Agua»,en La Gota de Agua. Hacia una gestión sustentable y democrática del agua, editado por Esch, Sophie, Fundación Heinrich Böll, México, pp. 255-264. 
Roth, Dik; Rutgerd Boelens \& Margreet Zwarteveen, 2005, Liquid Relations. Contested Water Rights and Legal Complexity, Rutgers University Press, New Jersey.

Ruiz, Laura, 2005, «Gestión de recursos naturales y relaciones de género en el Ejido Benito Juárez, Mpio. La Concordia, Chiapas», en Relaciones de Género y Acceso a la Tierra, editado por Arturo León, Elsa Guzmán, Friné López, Julio Romaní y Laura Ruiz, Espacio Autónomo, A. C. y UAM-Xochimilco, México, pp. 49-90.

Ruiz, Laura, 2009, «Transformaciones rurales, género y derecho al agua y a la tierra en Chiapas. Un estudio de caso en el Valle del río Grijalva», Tesis de doctorado en Sociología, ICSH-BUAP, México.

Ruiz, Laura. 2011. «Gobernabilidad del agua y equidad de género en el sector de la irrigación», en Tecnología y Ciencias del Agua, vol. II, núm. 3, julio-septiembre, pp. 219238.

Scott, Chris, 1996, «El nuevo modelo económico en América Latina y la pobreza rural», en La sociedad rural mexicana frente al nuevo milenio, coordinado por de Grammont, Hubert y Héctor Tejera, Vol. II, UNAM / UAM / INAH / Plaza y Valdés, México, pp. 83 -122.

World Water Council, 2002, Visión Mundial del Agua, Earthscan Publications Ltd., Londres.

Zwarteveen, Margreet, 2008, «Men, Masculinities and Water Powers in Irrigation», Water Alternatives 1(1), en: <www.water-alternatives.org> (consulta: 11 de marzo de 2009). 


\section{Notas}

${ }^{1}$ En los últimos años se han dado a conocer experiencias comunitarias de manejo de los recursos hídricos que postulan la necesidad de aceptar la existencia de diversos sistemas sociolegales que se encuentran en interacción, se complementan y con frecuencia entran en conflicto. Tal es el caso de los planteamientos del pluralismo legal que muestran cómo las legislaciones nacionales suelen ignorar la complejidad de las prácticas locales de manejo y gestión, así como las visiones sociales y culturales que interviene en la forma en que los diversos grupos sociales se relacionan con el agua y asignan derechos sobre su uso (Boelens, 2008; Roth, Boelens y Zwarteveen, 2005). De tal forma, la igualdad jurídica que establece la ley no puede hacerse realidad en contextos socio-culturales y económicos diversos y desiguales. Las leyes se basan en una visión normativa que pretende homogeneizar las formas de asignación de derechos a través de las concesiones establecidas por el Estado, dejando de lado las prácticas locales y las relaciones sociales y de poder existentes. El pluralismo legal propone comprender la coexistencia de varios esquemas legales e incorporar ambos en una perspectiva integradora.

${ }^{2}$ El 98.5\% de los usuarios del agua del distrito son ejidatarios y el 1.5\% propietarios privados.

${ }^{3}$ Desde 1982, año de inicio de operaciones del distrito de riego, la superficie de maíz crece de 856 hectáreas en 1982 a 1,877 hectáreas en 1994, pero a partir de este año, por efecto de la caída de los precios de las cosechas, la superficie de maíz experimenta un descenso para establecerse en 1,368 hectáreas en el ciclo 2005.

${ }^{4}$ El dominio pleno es un procedimiento administrativo que consiste en cambiar el régimen de las parcelas ejidales (propiedad social) y convertirlas en predios de propiedad privada.

${ }^{5}$ En el distrito de riego, el sector de propietarios privados está integrado por 25 usuarios, de los cuales solo tres son mujeres. Este sector social no fue incluido en el estudio.

${ }^{6}$ A partir de su relación de propiedad con la tierra el estatus social de las mujeres difiere. Las ejidatarias son titulares de un derecho parcelario, mientras que las posesionarias han accedido a una parcela de labor dentro del núcleo agrario y son reconocidas por la asamblea, pero no tienen el derecho de participar en las asambleas y en la toma de decisiones locales; son consideradas por la Ley Agraria como sujetos agrarios de segunda categoría. Sin embargo, el Procede les otorga un documento de propiedad con ese estatus. Las posesionarias suelen tener una relación de parentesco con algún ejidatario, de quien recibieron la tierra por herencia y cesión o mediante la compra.

${ }^{7}$ Según la Ley Agraria, las posesionarias no pueden vender la tierra, pues solo tienen el usufructo. No obstante, en los hechos lo hacen si tienen la necesidad. Además, cuentan con un documento de propiedad otorgado por el Procede y son reconocidas por la asamblea como poseedoras de tierra. En algunos casos, la transacción se establece mediante un contrato privado con el comprador, avalado por la asamblea. Asimismo, conviene recordar que, aunque la Ley Agraria prohíba la división del derecho parcelario y la venta de tierras (por "posesionarios" o ejidatarios) a personas ajenas al núcleo agrario, estas prácticas se realizan con suma frecuencia e imperan mecanismos no formales en los tratos agrarios. La mayoría de las transacciones no se comunican al Registro Agrario Nacional.

${ }^{8}$ De manera semejante, en su estudio realizado en el distrito de riego de la Comarca Lagunera, Alhers (2003) encontró que la venta es más común entre quienes dejan la agricultura, enfrentan enfermedad, no tienen mano de obra y están en cartera vencida.

Fecha de recepción: 7 de agosto de 2011.

Fecha de aceptación: 20 agosto de 2012. 